\title{
Three key points about the development of Higher Vocational Education
}

\author{
Chen $\mathrm{Yu}^{1, \mathrm{a}}$, Wang Jiajia ${ }^{1, \mathrm{~b}}$ \\ ${ }^{1}$ Taizhou Polytechnic College, Taizhou, Jiangsu, China, 225300 \\ axiaoyueryuchen@163.com, bWangjiajia_99@163.com
}

\begin{abstract}
Keywords: Higher vocational education, The quality, Key points, Exploration
Abstract:Problem, is the contradiction that real exists in the process of the development of things. The important problem is the most extensive and profound part. To improve the quality of higher vocational education, it is the most basic requirements and the most fundamental mission to discover and put forward the problems in educational process of higher vocational education. Only efforts to find, put forward the basic issue, the core issue and the key issue one by one, and carefully analysis, actively explore solutions to meet the needs of the actual, the improvement of the quality of higher vocational education is likely to become a reality.
\end{abstract}

\section{Introduction}

The Recommendations of CPC Central Committee on the Formulation of National Economic and Social Development of the Thirteenth Five Year Plan, which passed in the fifth Plenary Session of the 18th CPC Central Committee (hereinafter referred to as The Recommendations), emphasis on improving the quality of education ${ }^{[1]}$, and clearly put forward the overall goals and specific tasks of education during the period of 13th Five-Year. Improving the quality of education, is the fundamental mission and eternal pursuit of education, and moreover is the front page headlines and top priority of the next five years of educational development strategy. As a very important part of edbiz, higher vocational education can not stay on the sidelines at ease.

Improve the quality of education, this is a clear requirement of the central government for all education, including higher vocational education, this is also an urgent need for the development of higher vocational education ${ }^{[2]}$. But we have to see clearly, to improve the quality of education is not an affair in one day, cannot be achieved overnight, but to fully understand the importance and difficulty of improving the quality of education, long time to work, to carry out the basic work in a down-to-earth manner, correctly handle the basic issue, the core issue and the key issue, and all kinds of major issues in the development, constantly opening up the new realm of improving the quality of higher vocational education.

\section{A Basic Question: Is the Level or Type of Higher Vocational Education}

In practice, a lot of higher vocational education workers have such doubts: the higher vocational education in our country belongs to the specialized level of higher education, or is a new type of higher education, or both, is a level, but also a type? If so, belong to what kind of level and type? It is related to how to reform and develop higher vocational education, how to do better. It essentially determines the orientation of higher vocational education, as well as the objective law and policies matching. Fundamentally speaking, this is the problem of the development concept of higher vocational education, is a very important basic issue.

Talking about the reform and development of higher vocational education, we must talk about the current situation of higher vocational education. China's higher vocational education started in the last century in 80 s, after more than 30 years of development, formed the situation today, the number of schools and the number of students have accounted for half of the higher education in China. But it does not match that, the public's understanding of higher vocational education is blurred. Policy is not matching, condition of running a school is not enough, the characteristics of running a school is not obvious. So to speak, the whole society is not ideal for higher vocational education, even some low. In recent years, some higher vocational colleges in Anhui, Shanxi, 
Shandong and so on had serious difficulties in recruiting students, this can not be said that the leaders of these institutions are not properly implement the policies and requirements of the above.

Edbiz is a very complicated system engineering, it is related to all aspects of society and thousands of households, up to the party committees and governments at all levels, medium to all walks of life, down to ordinary people, are closely related to the development of education all, it's not just about school. And at different levels, different types of education also have a close logical relationship, basic education, secondary education, higher vocational education, undergraduate education and graduate education, all have internal relations, and also have their own division of labor, if there is no clear positioning, it's easy to dislocation, then random force, and influence effect of running a school. So to speak, scientific orientation of running a school is the outline link of the reform and development of higher vocational education, other important factors are contents, each department in accordance with the inherent law of the development of higher vocational education and their own division of labor, promote the solid work, to form a resultant force, and truly improve the quality of personnel training, to make due contributions to coordinate the promotion of "four comprehensive" strategic layout, to win people's trust and support.

Someone support the view of type think, the higher vocational education should be treated as a new type of education, should include specialist, undergraduate, master and other levels. Someone support the view of level think, higher vocational education is only the specialized level of higher education in our country, higher vocational education should not be held at the undergraduate level, higher vocational colleges should stick to their own level of attention, do the characteristics of higher vocational education, focus on improving the quality.

So, now the two views coexist, intertwined with each other. On the one hand, the country strict control higher vocational colleges rise to undergraduate schools. On the other hand, the higher vocational colleges have a strong appeal to rise to undergraduate schools. Coexistence of these two perspectives, causes some vocational colleges' education and training target to blur, the quality of talent training can not be guaranteed. China control " vocational college rise to undergraduate school " have its reason, but higher vocational colleges also have their own reasons, the most important is to meet a lot of practical difficulties in the process of running a school: funding for education is low, and special funds are often not guaranteed; poor quality of students; cooperation with the enterprise is left out in the cold, hard to cooperate; the level of graduates' employment is low, social treatment is low, often be discriminated against etc. In addition, there is a reason for the tangle, even though the country is strictly controlled vocational college rise to undergraduate school, but every year there are some higher vocational colleges leave the higher vocational education team and rise to undergraduate school still, one of the most recent examples is Tianjin Sino-German Vocational Technical College. This is the first undergraduate school about applied technology education, it is established on the basis of the Sino German Career Technical College, integrate of Tianjin Haihe Education Park library education resources. And some colleges that rise to undergraduate schools, the qualities are not very good. This is bound to bring pressure to other colleges, and make it unable to be at ease to engage in higher vocational education.

May 2014, the State Council issued The Decision on Accelerating the Development of Modern Vocational Education, to explore the development of undergraduate level vocational education, to form of a clear positioning, scientific and rational structure of vocational education ${ }^{[3]}$. This is actually the concept of higher vocational education is a type, higher vocational education is not only an important part of the modern vocational education system, but also a kind of education type, including junior college, undergraduate two levels, in the future there will be a graduate level of vocational education. However, the state in The Decision about the higher vocational education is not format the system, many references are scattered in various parts, and it is difficult to operate in the practice of running a school. To implement the decision, in October 2015, the Ministry of education has issued The Action Plan for the Innovation and Development of Higher Vocational Education (2015-2018) ${ }^{[4]}$, further put forward to explore the level of undergraduate education in the form of vocational education, and system construction of college, undergraduate, professional degree graduate training system, but it's just a goal. Therefore, it is urgent to need system carding, 
scientific positioning. What is the standard of running a school of graduate level, undergraduate level, and higher vocational education, which colleges are engaged in these levels of vocational education, and how to name respectively, the three levels of high vocational education and secondary vocational education together how to link up each other. Now higher vocational colleges in the college level represent the vocational education, higher vocational colleges are renamed after upgrading. Take the above mentioned in the Sino German University of Applied Technology, school located in the application of technical types of higher education, mainly to cultivate the regional economic and social development needs of the application, technical and skilled personnel, both the undergraduate level of application of technology education, and the specialized level of higher vocational education are implemented, but from the name, there is no relationship with higher vocational education. So, how to distinguish college level, undergraduate level, the graduate level of higher vocational education with each other? How to carry out the reform of higher vocational education enrollment, how to ensure more high score students to accept higher vocational education? Only elaborating these questions and a series of related issues with a clear system, higher vocational education could really become one type. Otherwise, higher vocational education is in the intertwined, mutual entanglement of level and type still, thanks to coexistence of the two points of view, it is difficult to accurately grasp the objective law, reform is difficult to comprehensively promote, it is difficult to put the reform and development of vocational education issued by central and provincial, municipality.

\section{A Core Question: Whether or not The Scientific Research is Needed of Higher Vocational Education}

The controversy about whether to engage in scientific research in higher vocational education comes from some problems in the research work of higher vocational colleges. At present, a lot of higher vocational colleges pay attention to the papers, projects and awards, whether it is promotion or performance evaluation, are based on the it mainly. Papers, projects, awards and titles, performance are linked, the title, performance and salary is linked. In this evaluation system, a teacher even if his level is high, if there is no papers, projects, awards, will not be promoted to the corresponding title, not only can not get reasonable compensation, but also can not get social justice evaluation.

Under the guidance of this evaluation system, teachers publish papers, report projects, participate in the appraisal for conferring of acadmic title, and getting performance, rather than interest and practical needs, many people even think it is not important to improve the level of competence. So, many higher vocational colleges have appeared the situation that the number of papers, is not commensurate with the title level and teaching level. To a good teacher, papers, projects, and awards are not so many, teachers who have many papers, projects, and awards teaching level is not high, that is no longer a single phenomenon, also common in some colleges. There are some teachers whose teaching and scientific research is generally recognized as relatively high, but because there is no energy to engage in scientific research, there is not enough to meet the requirements of the papers, projects and awards, titles can not be promoted for a long time. In fact, it is a waste of time and energy, contributing to academic corruption, a direct impact on the core position of personnel training.

Therefore, in the face of such a "scientific research", many vocational education workers have doubts: The core task of higher vocational colleges is to train talents. The purpose is to serve the local people, what is the significance of such research, whether or not to do it? The answer is absolutely no. Higher vocational colleges must vigorously develop scientific research, if there is no high level of scientific research, it is difficult to cultivate high-quality technical personnel, which is the core of the development of higher vocational education. Some people may say that whether or not it impact the core task of personnel training with the vigorously development of scientific research in higher vocational colleges. This is obviously untenable, scientific research is the basic way to improve the level of teachers, is an important means to promote the comprehensive development of students, is the basic work to enhance the level of professional curriculum 
construction. Higher vocational colleges engage in scientific research not only will not charge personnel training, but also to provide a strong support for personnel training, the key lies in whether our scientific research is closely related to the objective needs of personnel training. Therefore, higher vocational colleges not only engage in scientific research is not wrong, but also should be advocated, but we advocate for "personal interests, work needs and exploration spirit", always adhere to the practice site, down to earth, dock the industrial development in depth research; in order to solve practical problems of higher vocational education and local economic and social development, for the purpose of improving the level of education, and personnel training in higher vocational colleges

\section{A key question: what is the innovation of Higher Vocational Education}

With "mass innovation" is increasing popular, the role of innovation are gradually elevated to an unprecedented height, in the fifth Plenary Session of the 18th CPC Central Committee, innovation and development is among the top of five major development, becomes a major strategic through throughout of the <The Recommendations $>^{[5]}$. Thoroughly implement the concept of innovation and development, promote the implementation of innovation driven development strategy, higher vocational colleges are no exception. But to combine the spirit of the the fifth Plenary Session of the 18th CPC Central Committee the same period, the Ministry of Education issued the Action Plan for Innovation and Development of Higher Vocational Education, identify the entry point and the breakthrough point, further promote the comprehensive innovation with scientific and technological innovation as the core, enhancing the endogenous motivation and development vitality of higher vocational education through comprehensive innovation, to enhance the overall strength of higher vocational education, personnel training structure is more reasonable, quality continues to improve, the ability to service manufacturing capacity of 2025 and the level of economic and social development significantly improved ${ }^{[6]}$. It can be said that this is a very important problem in the development of higher vocational education at present, only solve this problem, in order to realize the new development of higher vocational education innovation, achieve the "two for one hundred years" goal and the great rejuvenation of the Chinese dream to provide a solid guarantee.

A multitude of things work in higher vocational colleges, every work needs to improve quality and efficiency, we must further increase the intensity of innovation, width and depth. So, everyone of the higher vocational education workers must firmly establish a sense of innovation, enhance the consciousness and firmness of innovation, and actively participate in the flood of the "mass innovation", try our best for the innovation and development of higher vocational education. First, we must firmly establish the system thinking, solid progress in comprehensive innovation. Second, it is to firmly adhere to the problem oriented, targeted to carry out innovation. We want to combined with our own reality, identify the combination of points on the interface, grasp the difficulties, make the focal. In the first breakthrough of the institutional innovation, the innovation of talent cultivation model and other aspects, effectively promote the higher vocational education in the development of power, development mode, running status and other aspects of the important transformation, and on this basis, step by step, gradually expand the scope of innovation.

Here, we must also face some problems appeared in the process of innovation and development of higher vocational education, and to be improved effectively, especially under the guise of innovative characteristics to mess things up. Innovation has its inherent law and logic, any form of innovation, are not arbitrary, must have a solid foundation of reality. Only with solid foundation, innovation can achieve good results. In practice, we often see some units, some departments and some vocational colleges, blindly pursue the so-called "innovation", regardless of the objective reality, without carefully analysis, regardless of the actual effect, all in the name of "innovation", for this begin at the wrong end, drag hard, far fetched, give up halfway, in fact, this "innovation" with no association to the real innovation, must resolutely abandoned, efforts to innovate in the original, true face. 


\section{References}

[1] The Recommendations of CPC Central Committee on the Formulation of National Economic and Social Development of the Thirteenth Five Year Plan[S]. Beijing: People press, 2015.

[2] Yuan Guiren. Improve the Quality of Education[M]//Tutorial reader for The Recommendations of CPC Central Committee on the Formulation of National Economic and Social Development of the Thirteenth Five Year Plan. Beijing: People press, 2015.

[3] Guo Fa [2014] No. 19. Decision of the State Council on accelerating the development of modern vocational education[S].

[4] Ministry of Education, Jiao zhi cheng [2015] No. 9. Notice on Issuing The Action Plan for the Innovation and Development of Higher Vocational Education (2015-2018) [S].

[5] This commentator. The development of innovation in the core position of the country's overall development[J], Truth Seeking, 2015(23).

[6] Liu Yandong. Implementing innovation driven development strategy[M]// Tutorial reader for The Recommendations of CPC Central Committee on the Formulation of National Economic and Social Development of the Thirteenth Five Year Plan. Beijing: People press, 2015. 